\title{
LA CONSTRUCCIÓN DEL ESPACIO ÍNTIMO EN EL DIARIO LITERARIO $^{1}$
}

\author{
THE CONSTRUCTION OF THE INTIMATE SPACE ON LITERARY \\ DIARY
}

\author{
Álvaro LUQUE AMO \\ Universidad de Granada \\ luqueamo@correo.ugr.es
}

Resumen: El artículo plantea un acercamiento teórico-literario al diario personal para analizar la construcción del espacio íntimo en el texto diarístico. Con este fin, se desarrolla el concepto de intimidad desde ámbitos como la psiquiatría o la filosofía y se retrocede a los orígenes del diario personal para interpretar la construcción del espacio íntimo dentro de la manifestación que interesa a nuestro campo de estudio: el diario literario.

Palabras clave: Intimidad. Diario. Teoría de la autobiografía. Teoría de la literatura.

Abstract: This paper presents a theorical approach to personal diary with the aim to analyze the construction of the intimate space on diaristic text. To this end, we develop the concept of intimacy from the philosophy and

1. Este trabajo se ha realizado bajo el patrocinio de una Ayuda FPU concedida por el Ministerio de Educación, Cultura y Deporte. 
move back to the origins of the personal diary to understand the construction of the intimate space on literary diary, our field of study.

Key Words: Intimacy. Diary. Theory of Autobiography. Theory of Literature.

\section{LA INTIMIDAD 2}

\subsection{Lo íntimo}

El espacio de lo íntimo es problemático; de la intimidad se ha teorizado frecuentemente sin delimitar el ámbito de su definición. Partiendo de la distinción entre lo exterior y lo interior, considerando que lo público se contrapone a lo íntimo, se ha confundido en numerosas ocasiones el concepto de privacidad con el de intimidad, hasta el punto de que en el imaginario colectivo ambas formas se utilizan indistintamente. Si se acude al Diccionario de la Real Academia Española, por poner un ejemplo, se descubre que la quinta acepción del adjetivo íntimo, en su variante femenina, hace referencia a una comprensa higiénica en Cuba; si se desea describir los órganos sexuales del hombre o de la mujer, se recuerda otra construcción como la de partes intimas. La divulgación del término de forma errónea, en definitiva, obstaculiza una definición de lo íntimo que aquí será considerada el punto de partida.

Es necesario, en primer lugar, concretar el espacio de la intimidad.

2. En los últimos años, ha habido un incremento de estudios sobre el diario en España. En el centro de investigación SELITEN@T, de la UNED, se han llevado a cabo las investigaciones sobre autobiografía más innovadoras en el contexto español, entre las que destaca una continuada atención al diario personal como género literario. Sus publicaciones se pueden ver en http://www2.uned.es/centro-investigacion-SELITEN@T/ escritura_autobio.html [20/03/2017]. Una de las grandes publicaciones sobre escritura diarística en España es el número 182-183 de la Revista de Occidente, del cual se recogen aquí los artículos de Castilla del Pino (1996) y Alain Girard (1996). Además, como grandes ejemplos de investigadores que se han acercado al ámbito diarístico están los casos de José Romera Castillo (2000a; 2000b; 2004; 2006) o Anna Caballé (2015). Asimismo, ha habido trabajos que estudian directamente las relaciones entre diario e intimidad, como los de Laura Freixas (1995), Virgilio Tortosa (2000) o Manuel Hierro (1999). El más importante de estos últimos es el de Celia Fernández Prieto, publicado en 2015 en Revista de Occidente con el título "Diario e intimidad". Este artículo aborda algunas ideas que serán tratadas aquí, pero apenas se acerca a los problemas que implica la construcción literaria del espacio íntimo en el diario y los errores más comunes en su interpretación, que se intentarán analizar en las siguientes páginas a partir de la definición de lo íntimo y de una genealogía de la escritura diarística. 
Aunque en apariencia sean conceptos similares, la intimidad se diferencia claramente de la privacidad - terreno de la compresa y de las partes sexuales-. Para una mejor comprensión, debe introducirse un tercer elemento como es el de lo público. Un autor como Carlos Castilla del Pino define perfectamente estos tres espacios. Este explica (1989: 27) que las actuaciones públicas son aquellas "necesariamente observables (visibles, audibles etc.)"; las actuaciones privadas pueden ser observables "a poco que se den o la falta de cautela por parte del actor o el voyeurismo del observador"; y las actuaciones íntimas, en cambio, "no pueden observarse y solo se las puede inferir a través de lo que el sujeto dice o hace, incluso con su inhibición o su silencio". La diferencia esencial entre las actuaciones íntimas y el resto estriba en que las primeras nunca serán observables, porque carecen de la proyección externa de las otras. Acciones como fantasear, imaginar y, en suma, pensar, no poseen esa categoría externa que caracteriza a las públicas y privadas, por lo que "no pueden ser sabidas por nadie fuera del sujeto" (Castilla del Pino, 1989: 29). Lo íntimo, por tanto, y esto interesa para más adelante, nunca es comprobable, "ni por consiguiente su verdad o mentira" (1989: 29), porque se puede inferir a través de lo que se dice o se hace, pero jamás se tiene acceso a la intimidad, que es inobservable.

La intimidad, en palabras de Aranguren (1989: 19), es el repliegue de la persona sobre sí misma, la relación intrapersonal o intradiálogo, la re-flexión sobre los propios sentimientos. La intimidad es un ámbito, el espacio del ensimismamiento, el lugar del en-sí-mismo.

\subsection{Los límites de la intimidad}

En su libro titulado La intimidad (1996), José Luis Pardo dedica un capítulo del mismo a lo que denomina una "Fenomenología del espíritu íntimo". A lo largo de estas páginas, Pardo reconstruye el proceso que da lugar al acto íntimo; proceso que divide en tres etapas o momentos: un primer momento referido a la mismidad; un segundo relacionado con la alteridad; y un tercero en el que el Yo es consciente de la existencia de un Sí mismo, instante que denomina el momento de la estupefacción:

Primero el yo habla; después, el Sí Mismo repite lo que el Yo ha dicho o hecho, y finalmente, el Yo recibe el mensaje 
que él ha emitido, pero lo recibe reflejado por el Sí mismo. Cuando el proceso ha terminado, se ha completado también esa paradoja según la cual, para ser uno, hay que desdoblarse en dos (1996: 176).

De esta forma, el mejor modo de definir el espacio íntimo es considerarlo como ese espacio que es impenetrable para los otros: "nadie, salvo los íntimos, puede contemplarlo, reconocerlo, habitarlo" (1996: 161).

Si antes se señalaba que una de las grandes falacias relacionadas con la intimidad es la errónea cercanía que mantiene con el concepto de privacidad, Pardo señala otra: la falacia de la inefabilidad, que sostiene que la intimidad es lingüísticamente inexpresable (Pardo, 1996: 39). La intimidad, en cambio, no es inefable. La intimidad, según Castilla (1996: 22), pugna por exteriorizarse, bien hasta un ámbito privado - en la confidencia-, bien a uno público, como en la radio, televisión o, enmascarado, en la literatura. Las actuaciones íntimas pueden transformarse en privadas o públicas a través de su codificación verbal y/o extraverbal, y es por ello que se habla así de un diario íntimo, si bien como se verá más adelante esta locución tiene una naturaleza más retórica que referencial.

La intimidad puede comunicarse, pero su característica principal es que es inconfesable. Esta paradoja puede explicarse con facilidad: la confesión no puede ser nunca un acto solitario, no hay confesión sin confesor; de esta forma, la única manera de confesar la intimidad es hacerlo ante una persona, y en el momento en que la intimidad se revela, esta se destruye. Pardo (1996: 145) proporciona un ilustrativo ejemplo: unos amantes tienen una relación, una relación cuya intimidad no reside en el mero hecho físico, sino en los silencios, en aquella intimidad compartida que pertenece a los amantes, en lo que ellos han llegado a saber sobre sí mismos. Bien, en el momento en que cualquiera de los dos le comunique a un tercero cómo son estas relaciones, no podrá decirse que la intimidad ha sido revelada, sino más simplemente que ha sido destruida. Y quien destruye la intimidad destruye parcial o totalmente la verdad de los así traicionados, es decir, caricaturiza su vida. Esto va a resultar de gran importancia a la hora de analizar el Yo del diario personal cuando se constituye en Yo literario, pues en esa transición el Yo, en tanto que personaje, queda inevitablemente caricaturizado.

En último lugar, debe ser subrayado un hecho determinante: la 
intimidad, al menos su desarrollo y su concepción actual, no ha existido siempre, sino que por el contrario se relaciona con la evolución del concepto de individuo y de lo privado. Como señala Aranguren (1989: 19):

en continuidad con la privacy o vida privada, precondicionada por ella, surgió la intimidad, es decir, frente a la interpersonalidad de la vida privada, el nuevo repliegue, ahora de la persona sobre sí misma, repliegue que se manifiesta, empieza a manifestarse fisicamente mediante el establecimiento de la barrera de una comfortdistance (la del brazo extendido para dar la mano), opuesta al manoseo y arrejuntamiento antiguos, y en relación con ello, la vigencia social del pudor y, en fin, la creación de un "fuero interno".

La intimidad, en este sentido, solo puede considerarse a partir del surgimiento de la privacidad; por ese motivo merece la pena, sobre todo para entender los vínculos de la intimidad con el diario, acercarse a la genealogía de lo privado en su relación con la práctica del diario personal y su desarrollo como obra literaria.

\section{EL NACIMIENTO DEL ESPACIO PRIVADO Y LA POPULARIZACIÓN DEL DIARIO}

\subsection{Los orígenes de lo privado en el contexto de la nueva burguesía}

El desarrollo de lo privado está inevitablemente ligado a la nueva categoría que el sujeto adquiere a lo largo de los siglos XVIII y XIX, con el advenimiento de la burguesía y el paulatino asentamiento del Romanticismo en Europa. El Romanticismo va a suponer la confirmación de un Yo literario que se había insinuado en la escritura ensayística de Montaigne y sobre todo en Las Confesiones de Rousseau, quien inaugura con su obra un género que va a desarrollarse en los siglos posteriores: el autobiográfico. Como exponía Kant al declarar el fin de su minoría de edad (2004: 83), el hombre moderno reafirma la singularidad de su pensamiento, aquello que lo distingue del resto de los hombres y por tanto 
lo hace diferente, inevitablemente auténtico.

El auge del individualismo está relacionado además con las ideas que la Revolución francesa exporta al resto de países occidentales — si bien previamente ya se intuyen en la Revolución acontecida en Inglaterra, casi un siglo antes ${ }^{3}$ - y que se resumen en la confianza que la burguesía deposita en el individuo. El concepto de sujeto, tal y como expresa Sánchez Trigueros, se conforma progresivamente en beneficio de los ideales económicos y políticos de la burguesía (2013: 32). Señala Aranguren que el objetivo principal de la Revolución francesa, "convertir al cada hombre, $\mathrm{y}$ en especial, a quienes por pertenecer al tercero y último estamento carecían de toda participación política, en citoyens, en ciudadanos" (1989: 22), anticipa el inicio de la democracia moderna. Pronto, afirma Aranguren, el burgués elevado a ciudadano cae en el aburguesamiento y se hace "burgués en el peyorativo sentido romántico de interesado solamente en los asuntos de su vida privada, familiar y económica" (1989: 22). Esto propicia un estilo de vida que favorece, en última instancia, el desarrollo del ámbito privado ${ }^{4}$.

Este nuevo espacio encuentra su lugar en los dominios de la casa, "fundamento material de la familia y pilar del orden social" (Perrot, 1991: 9). En el seno de la pequeña burguesía, señala Corbin, prospera la alcoba individual; esta alcoba se convierte en el templo de la vida privada de la joven (1991: 142). Un hecho mencionado por Alain Corbin puede resultar indicativo de este proceso: la difusión del espejo como objeto del hogar. En las aldeas del siglo XIX, por ejemplo, "solo el barbero posee un verdadero espejo, reservado para el uso masculino" (Corbin, 1991: 125). Los vendedores ambulantes comercializan el espejo pequeño a fin de que las mujeres y muchachas puedan contemplarse en ellos, pero el campo, en general, ignora los espejos de cuerpo entero. En las clases acomodadas, además, el código de las buenas maneras “impondrá durante mucho tiempo a la muchacha que evite contemplarse desnuda, aunque no

3. Esta es la teoría de Steve Pincus (2013), que ve en la inglesa la primera revolución occidental.

4. A este respecto, afirma Helena Béjar: "El individualismo entraña una separación respecto a la 'gran sociedad' y el consiguiente aislamiento en compañía de 'los íntimos'. Distanciamiento de la esfera pública y retirada en la esfera privada son, pues, los dos movimientos que definen el fenómeno del individualismo. Asociada a esta noción se halla la de privacidad, que puede definirse como una esfera de soberanía individual libre de interferencias externas. Tanto el individualismo como la privacidad son ideas latentes a lo largo de la historia de la cultura occidental. Pero en su sentido moderno se desarrollan plenamente en el liberalismo del siglo XIX”(1989: 51-52). 
sea más que en los reflejos del baño" (Corbin, 1991: 125) e incluso se venden polvos especiales que enturbian el agua con el objetivo de prevenir esa visión. A final de siglo, el espejo alcanza su definitiva difusión en los hogares, facilitando así lo que Corbin denomina "la organización de una nueva identidad corporal" (1991: 125). Esta genealogía del espejo ilustra no solo acerca de las limitaciones de la identidad individual a principios de siglo, sino que evidencia algo más importante: la aparición de un objeto que proporciona uno de los pocos episodios de privacidad $-\mathrm{y}$ derivada de ella, intimidad - para el ser humano de la época: la contemplación, a solas, de su propio cuerpo.

En suma, en el siglo XIX tiene lugar el surgimiento del ámbito privado en Europa, y con ello la democratización de lo íntimo. En este contexto puede entenderse la popularización del cultivo de una práctica como el diario personal, que Celia Fernández, siguiendo a Philippe Ariès, relaciona con tres factores político-culturales (2015: 50): la extensión de la intervención del Estado a parcelas antes ajenas - lo que Foucault identificó como el nacimiento de la biopolítica-; las reformas religiosas católicas y protestantes que postulan una piedad más personal y una devoción interior - la mística, la oración mental-; y la progresiva alfabetización que permite al individuo emanciparse de una cultura oral que le ligaba a la comunidad. Estas tres circunstancias favorecen, en conclusión, la generalización de la práctica del diario personal.

\subsection{La aparición de la práctica diarística}

Antes de entrar en materia, y como se deduce de lo anterior, debe diferenciarse entre el diario personal como documento y lo que aquí se denomina diario literario. En el primer caso se entiende el texto como documento derivado de la práctica cotidiana del diario personal; en el segundo, como la elaboración retórico-literaria de tal práctica. La confusión entre ambas formas ha acarreado notables problemas en los estudios sobre escritura diarística y además dificulta su periodización.

Recogiendo las ideas expresadas, se puede asegurar que la práctica del diario personal se desarrolla sobre todo a lo largo de los siglos XVII, XVIII y XIX, a partir de las circunstancias derivadas de la nueva sociedad ilustrada. La progresiva alfabetización de las clases burguesas europeas permite así no solo la consolidación del sistema literario - cuyo 
asentamiento se produce, sobre todo, a lo largo del siglo XIX-, sino también la proliferación de una nueva clase de textos: los textos personales, entre los que pueden incluirse epístolas, ensayos, autobiografías y diarios. La nueva individualidad de estos siglos posibilita la institucionalización del sujeto autor y con esta figura nace la importancia de la firma y la autoconsideración literaria. Aparejada a esta individualidad, y fomentada por el nuevo espacio privado del hogar burgués, la intimidad del estudio propicia la aparición de textos - que, en principio, no están pensados para la publicación - en donde el autor desarrolla los aspectos cotidianos que le conciernen. El diario personal, en este contexto, es el instrumento por excelencia de registro cotidiano. Su carácter a priori secreto, además, fomenta la construcción de lo íntimo en un ambiente en donde el sujeto empieza a considerarse a sí mismo como tal, de modo que a lo largo de los siglos XVII y XVIII se populariza su uso como cuaderno personal, como documento que privilegia la confesión secreta de los asuntos más reservados del diarista y la introspección cotidiana. Hasta tal punto es así que, cuando muchos de estos textos empiezan a publicarse a lo largo del siglo XIX, se acuña el término de diario íntimo por los editores de Amiel (Picard, 1980: 118) y esta denominación pasa a ser de uso común en determinados contextos para definir al nuevo género literario.

Sin profundizar aún en esto, es necesario mencionar que la práctica del diario, a pesar de su desarrollo en la modernidad, tiene unos antecedentes a los que algunos autores se han aproximado. La práctica del diario personal, a este respecto, posee una particularidad que condiciona su genealogía: es un texto que está escrito, en origen, para uno mismo, de tal manera que resulta muy difícil, en la medida en que durante grandes épocas fue una escritura que no salió a la luz, determinar su nacimiento e incluso intuir su evolución. Es posible, sin embargo, rastrear sus orígenes en manifestaciones como los hypomnemata, cuadernos personales destacados por Foucault que "podían ser libros de contabilidad, registros públicos, cuadernos individuales que servían de ayuda-memoria" (1999: 292); en los diarios de navegación - como en el caso paradigmático del diario de Cristóbal Colón- mencionados por Andrés Trapiello (1998: 33); o en los libros de cuentas a los que se refiere Anna Caballé (2015: 64), que se manifestaban como registros de propiedad en los que se acumulaban todos los sucesos que interesaban a la contabilidad económica de la familia e incluso las veleidades artísticas y literarias de sus autores (Luciani, 2013: 
192). Esos antecedentes, ante todo, tienen una cualidad testimonial y pública, y resultan aquí de interés porque le otorgan a la práctica del diario un carácter público que esta pierde progresivamente. De esta forma, una práctica de carácter público como la de registrar los sucesos en papel de forma cotidiana, a modo de una contabilidad doméstica o profesional, pasa a ser una práctica individual y privada con la que el individuo empieza a desdoblarse en la página, construyéndose como Yo protagonista textual.

Esta evolución se registra, sobre todo, a lo largo de los siglos XVII, XVIII y XIX, en las tradiciones anglosajona y francesa. El diario se convierte entonces en una tarea diaria, pasando a ser, en palabras de Alain Corbin, una "disciplina de la interioridad" (1991: 159). Es así extraordinariamente conocido el caso de Samuel Pepys, político inglés del XVII cuyo diario es el primero en mostrar una profundidad introspectiva que posibilita, como más tarde apuntaremos, una lectura literaria del diario personal.

\subsection{EI diario literario}

¿Cuándo el diario deja de ser producto de esa disciplina de la interioridad y pasa a ser considerado como una forma textual y autobiográfica más? ¿Cuándo, en definitiva, el diario deja de ser solo una práctica individual y solitaria y pasa a ser un texto que tiene la posibilidad de entrar en el sistema literario? Evidentemente, cuando se publican los primeros diarios personales y los diaristas empiezan a tener constancia de las posibilidades de publicación, a lo largo de todo el siglo XIX y durante el siglo XX. En este sentido, es importante aclarar que el origen del diario personal desde nuestra perspectiva solo interesa en relación a su publicación y no tanto en lo que concierne a su práctica, de tal manera que podría considerarse como un género propio de la Modernidad, tal y como han apuntado autores como Trapiello (1998) o Susan Sontag (2014). Así, aunque muchos diarios son escritos en los siglos XVII y XVIII, lo cierto es que estos diarios no se publican hasta varios siglos después, de tal manera que no es hasta bien avanzado el siglo XIX cuando se puede hablar de una auténtica escena diarística ${ }^{5}$. Por ejemplo, el diario de Samuel Pepys, que

5. Eusebio Cedena Gallardo realiza en su tesis de doctorado, dirigida por el prof. Romera Castillo, un recorrido cronológico del diario bastante exhaustivo. Algunas de las fechas que se recogen aquí se citan en su trabajo El diario y sus aplicaciones en los escritores del exilio español de posguerra (2004). Esta investigación se basa, a su vez, en muchas de las revelaciones que Granell y Dorta (1962) llevaron a cabo en su famosa 
es el más relevante en el contexto inglés, si bien escrito entre 1660 y 1670 , no se publica hasta 1825; el diario de John Evelyn, compuesto entre 1640 y 1706 y cuya publicación influye en la posterior recepción del diario de Pepys, no es publicado hasta 1818; pese a que otros diarios como el de John Wesley o el de Georges Fox son publicados con anterioridad a estas fechas, estos diarios no son propiamente personales e incluso en el caso de Fox se trata más bien de una autobiografía ${ }^{6}$. Ya avanzado el siglo XIX, se producen las publicaciones de otras obras como el diario de B. R. Hildon, en 1853, y el de autores conocidos como Walter Scott, en 1890. En el caso francés, por otro lado, y si es cierto que el famoso anónimo Diario de un burgués en París haría retroceder hasta el siglo XV, no es hasta el siglo XIX cuando empiezan a encontrarse los primeros diarios personales de relevancia: uno de los primeros diarios publicados es el de Maine de Brien, en 1834, que está escrito a finales del siglo XVIII y principios del XIX, en una época muy cercana al famoso diario de Stendhal, gestado a principios de siglo y publicado en 1888 ; en 1862 se publican también ${ }^{7}$ los diarios de Maurice de Guérin y a finales de siglo es publicado a su vez el diario de Benjamin Constant, texto muy valioso que ve la luz en 1895. En España, salvo raras excepciones como un extracto del diario de Leandro Fernández de Moratín, que se publica en sus Obras póstumas (1867) y que apenas puede considerarse un diario personal, los primeros diarios publicados se remontan directamente al siglo XX, como es el caso del diario de Jovellanos (1915), el diario de Alejando Sawa, Iluminaciones en la sombra (1910), o los acercamientos al diario de Azorín desde la novela y el ensayo $(1897,1901)$, que demuestran la popularización de esta forma.

Este repaso histórico conduce a la idea de que, efectivamente, no es hasta bien entrado el siglo XIX cuando el diario adquiere su estatus literario. La publicación en 1882 del Diario íntimo de Amiel, que va a

antología.

6. El clérigo anglicano John Wesley publica entre 1735 y 1790 extractos de un diario que abunda en una mirada exterior y escasamente introspectiva (el objetivo de Wesley era mostrar sus experiencias y sus conocimientos como religioso); el cuáquero Georges Fox publica sus llamados diarios en 1694, pero la lectura de estas páginas delata más bien una escritura autobiográfica que, como ocurría en parte con Wesley, se ciñe al hecho religioso con el objetivo de adoctrinar. Estos dos casos sí ilustran, en todo caso, la poderosa relación que hay entre el diario personal y el hecho religioso.

7. Esta del medio siglo es una época muy propicia para la publicación de diarios: en 1860 se publica el diario de Olivier Lefevre; en 1857 el diario de Rober Arnauld d’Andilly; en 1857 también los diarios de René Louis de Voyer de Paulmy. Todos estos autores escriben sus diarios con varios siglos de antelación a la publicación. 
ser considerado por lo general como el primer diario literario moderno, corrobora este hecho. Precisamente se trata del primer diario que incorpora en su título el adjetivo íntimo, como se ha dicho antes, lo que va a resultar interesante toda vez que ya se relaciona directamente el cultivo del diario personal con esta esfera privada que favorece la escritura del examen de conciencia diario.

El paso de práctica privada y secreta a texto público y susceptible de ser considerado literario ha sido destacado por autores como Alain Girard (1996). Otros autores, además, han interpretado esta evolución como el fin de una verdadera escritura íntima, en tanto que con la posibilidad de la publicación el diarista cambia drásticamente su enfoque. Como trataremos de definir a continuación, este punto de vista confunde la intimidad con la construcción textual de lo íntimo. Precisamente, y a modo de paradoja, cabe apuntar que el primer diario en ser denominado como íntimo, el de Amiel, es también el primero en ser concebido para su publicación, tal y como asegura Picard ${ }^{8}$. A partir del diario de Amiel, numerosas publicaciones de diarios incorporan el adjetivo íntimo en el título, y con el paso de los años se convierte en la etiqueta que singulariza la forma del diario personal frente a otras manifestaciones. Puede entenderse así el carácter retórico de una etiqueta que categoriza como íntimo un texto que justamente entonces pasa a ser público.

El diario literario, en suma, es un texto que deriva de una práctica individual y privada — en muchas ocasiones secreta - como es la de llevar un cuaderno de anotaciones cotidianas, una práctica que se desarrolla en un contexto determinado como es el de la creciente burguesía de los siglos XVII, XVIII y XIX. A partir de la publicación de este tipo de textos, a partir de su comercialización y su divulgación, nace un género literario de carácter autobiográfico que tiene su origen a finales del siglo XIX y que se asienta a lo largo de todo el siglo XX. En la larga transición que comprende el periodo desde que estos textos se publican a lo largo del siglo XIX hasta que se crea un contexto literario y un público que justifica esta publicación, muchos de estos textos siguen escribiéndose en la privacidad del individuo $-\mathrm{y}$ su carácter secreto propicia, en muchas ocasiones, una aparición póstuma - y otros se publican cuando el autor todavía vive-

8. Tanto Picard (1981: 118) como Monnier (1981: 92) aseguran que Edmund Schérer y Fanny Mercier cumplen con la voluntad del escritor suizo al publicar la primera parte de su diario personal. 
como es el caso de César González-Ruano en España-, pero ninguno de estos dos condicionamientos interviene en la construcción del espacio íntimo en el diario, que, más que tratarse de un elemento condicionado por el paratexto, obedece sobre todo a razones literarias.

\section{LA CONSTRUCCIÓN DE LA INTIMIDAD EN EL DIARIO LITERARIO}

\subsection{Lo íntimo como construcción textual}

La relación entre el diario literario y lo íntimo posee, como se ha visto, una problemática principal: cuando el diario pasa a ser publicado y el diarista toma conciencia de las posibilidades de publicación, sostienen muchos autores, hablar de intimidad en el diario carece de sentido. Alguien como Laura Freixas, en este sentido, llega a decir: "o se escribe un diario íntimo, pero no se publica, o se publica un diario, pero no es íntimo" (1995: 41).

Esta postura, a nuestro juicio, está mal enfocada, puesto que relaciona directamente la construcción de lo íntimo con el carácter secreto o no del texto diarístico, como si solo el diarista que mantiene su diario en secreto y no piensa en la divulgación de la obra pudiera construir un espacio íntimo en tales páginas. A esta perspectiva errónea ha contribuido sin duda el término de diario íntimo, que en muchas ocasiones no se ha interpretado como lo que realmente es: una forma retórica para definir un texto que, en tanto que público, no puede ser íntimo - lo que no impide que se pueda construir un espacio textual que aquí denominamos íntimo.

Si se vuelve a las primeras páginas de este trabajo y se retrocede hasta las ideas de Carlos Castilla del Pino, José Luis Pardo y José Luis López Aranguren a propósito de la intimidad, hay que recordar que la intimidad no es inefable. La intimidad se puede decir; por ese motivo, tiene bastante sentido que el diario desarrolle lo íntimo. Ahora bien, lo íntimo es también aquello inobservable, aquello a lo que no se tiene acceso desde el exterior, de tal modo que cuando el diarista traduce su intimidad a la página, cuando la desarrolla en el texto, no quiere decir que pueda mostrar la intimidad, 
sino como mucho, y estas son palabras de Castilla del Pino ${ }^{9}$, verbalizarla. De hecho, las actuaciones íntimas que el diarista codifica verbalmente se transforman, como mínimo, en privadas ${ }^{10}$ : el de diario íntimo, en este sentido, es un simple apelativo retórico para el diario personal cuya denominación más adecuada sería, posiblemente, la de diario privado. El diario personal entendido como práctica, en resumidas cuentas, puede decir y dice la intimidad; sin embargo, las palabras que narran lo íntimo no son lo íntimo, de tal manera que ni siquiera el diario más secreto puede ser íntimo. La publicación del diario, en última instancia, evidencia el carácter artificial de la intimidad narrada.

Si lo que el diarista narra en su diario no es, en definitiva, lo íntimo, ¿cómo podemos definir este espacio? La respuesta es sencilla: la intimidad que se desarrolla en el diario personal es, como todas las formas lingüísticas, una construcción. La intimidad, que siguiendo a Castilla no puede mostrarse, se construye en el texto mediante palabras, y en ese paso de verbalización la intimidad presentada en el diario ya es otro tipo de intimidad; en opinión de Antonio Moreno (2012), se podría hablar de una intimidad literaria. A este respecto, César Aira desarrolla en "La intimidad" (2008) una idea reveladora: en la intimidad hay una resistencia al lenguaje. Si, como se veía antes, es cierto que la intimidad puede decirse, hay que asumir que "la frontera de la intimidad retrocede tanto como avanza la voluntad de contarla" (2008: 3). En esta misma línea, José Luis Pardo hacía hincapié en la característica inconfesable de la intimidad; cuando la intimidad se confiesa, como ocurre con el diario personal que se publica, se destruye, y ridiculiza la verdad de los protagonistas traicionados. Por ese motivo, el protagonista de un diario - se puede pensar en Andrés Trapiello, pero también en Iñaki Uriarte e incluso, de cierta forma, en Amiel - suele tener reminiscencias irónicas. Fernando Pessoa, en El libro del desasosiego, declara: "Mi figura humana, si la consideraba con una atención exterior, era la del ridículo que todo lo humano asume cuando es íntimo" (Pessoa, 2013: 38). La ridiculez se relaciona así con el problemático ejercicio de transformar en lenguaje, instrumento público por excelencia, lo que nace

9. Dice Castilla del Pino: "Las actuaciones íntimas pueden ser, y lo son muchas veces, referidas, narradas, en suma, comunicadas mediante el lenguaje o la expresión no verbal, pero esto no las convierte, en puridad, ni en privadas ni en públicas. La comunicación de lo que imaginamos es, todo lo más, la verbalización de lo imaginado, pero no la mostración de lo imaginado. Lo íntimo puede decirse, no mostrarse" (1996: 19).

10. Señala Castilla del Pino: "Las actuaciones íntimas pueden transformarse, con mejor o peor fortuna, en privadas o públicas a través de su codificación verbal y/o extraverbal” (1996: 30). 
y se forma en nuestro interior, en nuestra intimidad; lo que, debido a la confrontación de espacios, da como resultado estampas frecuentemente ridículas.

En esta línea, César Aira añade algo que se anticipaba en el primer párrafo: "Es bastante evidente que la creación de intimidad se parece mucho a la creación de literatura" (2008: 5). La intimidad en el diario se interpreta entonces como una construcción, como una creación que acomete el hombre cuando verbaliza su pensamiento íntimo y que, frente a la intimidad original, resulta un evidente artificio tan retórico como el nombre de diario íntimo. La intimidad de un diario - también en el caso del diario privado o el documento diarístico sin publicar-, por tanto, puede existir, pero no es la intimidad en su medida exacta, sino su verbalización, posiblemente su literaturización.

\subsection{Intimidad y literatura}

En el caso del diario literario, forma que aquí nos interesa, lo íntimo se revela como una construcción que precisamente fomenta el carácter literario del texto. Para entender esto, hace falta recurrir a la problemática clásica de los estudios sobre escritura autobiográfica a propósito de la verdad del texto narrado. Bien, en el caso del diario literario, entender lo íntimo como una construcción no quiere decir, en cambio, que los acontecimientos narrados no tengan una correspondencia con la realidad. La intimidad del diario personal, en este caso, no es incompatible con la sinceridad, ni con el pacto autobiográfico de Lejeune (1994); más allá de eso, no se mide en tales términos. El propio Castilla del Pino mantiene que al respecto de la intimidad se puede mentir: "lo que se dice acerca de lo que se pensó, imaginó (...) puede no corresponderse con lo que fue pensado, imaginado etc. En todo caso no hay comprobación empírica posible" (1996: 19). Es en este punto cuando resulta interesante retroceder al concepto de intimidad sostenido antes.

El diario personal, como sucede con todas las formas autobiográficas, tiene una relación problemática con la literatura. Desde la perspectiva que se enfoca este artículo (Luque Amo, 2016), el diario puede ser literatura porque, cuando es un diario literario y no un mero documento -única forma a la que se opone el diario literario-, se construye con los mismos materiales de la ficción y porque, a pesar de respetar el pacto 
autobiográfico de Lejeune, según el cual los hechos narrados tienen una clara correspondencia con la realidad, no es verdadero o falso desde un punto de vista científico o histórico, sino que se ubica en el mismo terreno de la literatura. Bien, el concepto de intimidad que se deduce de las líneas anteriores, fruto de una construcción que el diarista acomete para hacer de su Yo íntimo un Yo diarístico, se sitúa en un terreno muy parecido al mencionado. La intimidad del diario personal no es así falsa, ni mentirosa, ni tampoco verdadera; la intimidad del diario personal es literaria. Hay un hecho que puede resultar ilustrativo a este respecto. Curiosamente, a lo largo de la evolución del diario personal, y al contrario de lo que podría parecer, el diario personal va adquiriendo independencia de las otras formas - el libro de cuentas o el diario de navegación - a medida que potencia e intensifica su faceta introspectiva. Por este motivo los primeros diarios que pueden ser interpretados desde la literatura son los de Samuel Pepys, los de Benjamin Constant o el mencionado de Amiel; porque desarrollan por primera vez esa mirada ensimismada. Al mismo tiempo, son estos diarios los primeros que se consideran literarios: por ejemplo, Laura Freixas señala las características que hacen del texto diarístico de Amiel un texto literario (Freixas, 1996). En este sentido, todo el mundo tiene claro que un libro de cuentas o un diario de navegación al uso no poseen nunca un carácter literario y su verdadera naturaleza es documental; sin embargo, el diario literario adquiere su identidad precisamente cuando refuerza la parte personal de su estructura, cuando muestra el Yo del diarista en toda su plenitud.

No es difícil, por tanto, llegar a la siguiente conclusión: el aspecto íntimo del diario personal potencia su carácter literario. Efectivamente, el diarista construye una imagen de sí mismo; esa imagen se corresponde con la realidad desde un punto de vista pragmático, pero no es la realidad. La intimidad que aparece en el diario es una construcción que resulta básica en la configuración de un Yo diarístico que está diseñado, precisamente, con los materiales propios de la ficción. La intimidad del diario personal es un artificio, tiene una categoría literaria en la medida en que no es una verdad científica o histórica — toda vez que no es comprobable- y finalmente contribuye a la literariedad del diario; de ahí que el diario literario sea un texto en donde, por encima de todo, prima el desarrollo del Yo. No por otra cosa mantiene Borges que Montaigne, un escritor sin lugar a dudas literario, es el padre de la intimidad (2007: 521). Posiblemente, el padre de 
la intimidad literaria.

En el diario literario, por tanto, se desarrolla la construcción de una intimidad autobiográfica, de una intimidad que consiste en la reflexión del diarista sobre sí mismo, en la introspección cotidiana que acomete el autor del diario. Esta dimensión del diario literario desemboca en la construcción de un espacio que aquí llamamos íntimo y que se construye, como se ha mencionado antes, mediante herramientas lingüísticas y en última instancia literarias. El carácter artificial, constructivo, de este espacio íntimo no lo contrapone, sin embargo, a lo verdadero del discurso autobiográfico, así como tampoco induce a pensar en la pérdida de la intimidad que otros autores han anunciado a propósito de su publicación.

\subsection{La intimidad del diario en el contexto actual}

En la polémica diario literario-intimidad que anunciábamos en el primer punto, por tanto, concurren normalmente dos errores principales: separar lo literario de lo autobiográfico - como si el hecho de que el diario se publicara le impidiera ser lo que realmente es: no la realidad, sino una construcción a partir de la misma que respeta el pacto autobiográfico-y asociar lo íntimo a lo privado. Así, es un error considerar que la intimidad del diario se ve resentida en los diarios pensados para publicarse. Un diario no es más íntimo por mostrar la desnudez del autor, sus vicios, sus miserias. Decir esto sería confundir intimidad con privacidad; implicaría considerar que un diario es más o menos íntimo por los acontecimientos privados que narra, cuando lo que aquí se ha entendido como intimidad en el diario personal es un elemento muy distinto a eso. Por ejemplo: en un diario como el de Sándor Marái, pensado para la publicación, concurre la misma construcción de la intimidad que en el diario de Samuel Pepys, escrito siglos antes de su publicación e incluso contando con la voluntad explícita del autor para dificultar su lectura ${ }^{11}$.

A pesar de lo anterior, muchos autores han querido plantear cómo el cambio de cosmovisión producido por la publicación del diario ha reducido la aparición de intimidad en sus páginas. Laura Freixas, en su artículo "La perdida intimidad en el diario íntimo" (1995), reflexiona acerca de la incapacidad del diario moderno para reproducir estas páginas

11. Como es sabido, Samuel Pepys ideó un lenguaje encriptado para su diario. 
introspectivas. Sin embargo, cuando la autora se acerca al concepto de intimidad, ella misma proporciona la siguiente definición:

Podemos sugerir que la intimidad, tal y como la practicaron los grandes diaristas, consiste en la introspección, la exploración de las propias emociones, el soliloquio moral, aunque enraizado siempre en lo concreto, en lo cotidiano, en la vida diaria del autor (Freixas, 1995: 37).

Bien, tomando esta definición como referencia, puede acudirse al diario de González Ruano para comprobar cómo el autor construye a la perfección una intimidad basada en la cotidianidad de su autor; al diario de Carlos Edmundo de Ory en que el autor se comporta de manera semejante; a los de Rosa Chacel; incluso en los diarios de Andrés Trapiello, que Freixas analiza para concluir lo contrario, se observa una profunda introspección: una introspección, claro, que no consiste en hablar de sexo o de episodios oscuros a la manera de una Anaïs Nin - más amiga del escándalo que de desarrollar su intimidad-, sino en una mirada interior que se muestra explícita en muchas ocasiones y que, en otras, se deduce de lo exterior. Cuando Trapiello (1990-2015) habla del ambiente familiar de su casa en Madrid, de las disputas con su vecino en Las Viñas, e incluso cuando sugiere que su esposa tiene un tumor, el autor, además de desarrollar su privacidad en el texto, está haciendo un profundo ejercicio de introspección. Por ello, planteamientos como el siguiente de Laura Freixas resultan, desde esta perspectiva, erróneos. Esta teoría, como la de Picard (1981), está presa del accidente de la no publicación ${ }^{12}$ y no asume por tanto el carácter de artefacto que tiene la intimidad, definida en estas páginas como una construcción. El nuevo diarista, como el antiguo, el previo a la consideración del diario como forma editorialmente comercial, diseña un espacio íntimo que en nada tiene por qué diferenciarse del ideado por Pepys, Constant o, tiempo más adelante, Amiel. Como señala Celia Fernández, "lo íntimo del diario no es pues una realidad dada, que exista fuera de o antes del lenguaje, sino un efecto de las palabras" (2015: 65). Este efecto, esta construcción que es, como se ha definido, la intimidad del diario, pugna por exteriorizarse en el caso de los nuevos diaristas como antes ocurría con los antiguos, y no se

12. En estos mismos términos lo expresa Manuel Hierro (1999: 104). 
detiene ante las consecuencias de una posible publicación.

Enmuchas ocasiones, esta confusión ha ido aparejada a la circunstancia de llamar a la práctica del diario personal y el texto resultante como diario íntimo, y además aplicarlo al diario que después aparece póstumamente - pues esta es la forma habitual en la que han ido surgiendo los diarios a lo largo del siglo $\mathrm{XX}$ - en forma de libro. Bien, la de diario íntimo, como se ha dicho, es una etiqueta que ponen en circulación los editores del diario de Amiel y que tiene especial relevancia en el contexto francés, en la medida en que otros diarios se publican con este apelativo, mientras que en el ámbito anglosajón es inexistente. En el contexto español tiene un recorrido bastante corto pero, a pesar de que en la actualidad son pocos los diarios que se publican bajo esta etiqueta ${ }^{13}$, en los estudios sobre diario y literatura suele ser empleada con asiduidad. Esta denominación, sin embargo, puede inducir a confusión toda vez que, a partir de ella, algunos autores han relacionado el carácter secreto del diario con la construcción de la intimidad en el texto, y solo los diarios que se han publicado tras la muerte del autor han sido considerados como verdaderos poseedores de un espacio íntimo. Más allá de censurar o no el empleo de esta etiqueta, hay que diferenciar en todo caso entre el diario personal como práctica y el diario literario ${ }^{14}$, y en el caso de emplear diario íntimo en lugar de diario literario - lo que hacen autores como César González-Ruano, cuando este publica partes de su Diario íntimo en el periódico-, debe tenerse en cuenta el carácter artificial de la intimidad y, en definitiva, la construcción de ese espacio textual llamado íntimo, como hemos hecho a lo largo de estas páginas.

13. Si se observan, en el ámbito hispano por tomar un eje referencial, los diarios personales publicados con posterioridad a 1950, se percibe la escasa aparición de diarios que se denominen, en el título, como íntimos.

14. En España se ha hablado de una forma como el dietario, que en muchas ocasiones ha sido definido como una manifestación diferenciada del diario en la medida en que su escritura muestra una ausencia casi total del Yo y, aunque dividido en entradas, una estructura muy similar a la del ensayo. Si se profundiza en la naturaleza de algunos dietarios, como puede ser el caso del dietario de Pere Gimferrer, se corrobora esta impresión, pues su escritura es eminentemente ensayística; sin embargo, también hay pasajes de este texto en los que el Yo cobra una importancia tal que se aproxima al Yo diarístico de cualquier diario literario. Más acentuada es esta circunstancia en un dietario como el Enrique Vila-Matas, que, aunque con los mimbres propios de una novela autoficcional, desarrolla también el ámbito de un Yo muy personal. Esto conduce a pensar, efectivamente, que las fronteras entre diario y dietario son más bien difusas, hasta el punto de que muchos autores hablan indistintamente de dos formas que realmente han acabado por no diferenciarse en las últimas décadas. El diario literario engloba, en última instancia, a todas las formas diarísticas que, y esa es su mínima condición, desarrollen el ámbito del Yo; un ámbito que tradicionalmente se ha identificado con lo íntimo. 


\subsection{La construcción del espacio íntimo en el diario literario. Conclusiones}

A modo de conclusión, se puede definir la práctica del diario personal como un ejercicio cotidiano y privado que se generaliza en los siglos XVII, XVIII y XIX, a partir de las nuevas ideas desarrolladas por la Ilustración en el contexto de la burguesía. En el diario personal el nuevo individuo se somete a un examen de conciencia laico y escribe textos en donde suele llevar a cabo un ejercicio de introspección, hasta desarrollar en muchas ocasiones un espacio íntimo. A lo largo del siglo XIX estos textos empiezan a publicarse y dan lugar a una nueva categoría que poco a poco logra formar parte del sistema literario: el diario literario. Este texto, que adquiere gran importancia en la literatura contemporánea - en la actualidad el número de diarios editados crece cada año-, mantiene a pesar de su publicidad la construcción del espacio íntimo como una de sus características narrativas esenciales. Lejos de condicionar su carácter literario, el desarrollo de un espacio íntimo, de confesión personal, potencia el carácter ficcional del texto, en la medida en que desarrolla el mundo subjetivo del protagonista, el Yo diarístico, que se conforma en el texto como un personaje literario. A pesar de lo que han sostenido algunos autores, por tanto, lo íntimo no se contrapone a lo literario; por contra, favorece la lectura literaria del diario.

Cabe aclarar, en relación a lo anterior, que no todos los diarios personales publicados pueden ser considerados diarios literarios. En estas páginas se diferencia entre el diario entendido y publicado como documento - aquel texto diarístico compuesto a partir de anotaciones puramente referenciales que no desarrolla unos elementos narrativos- y el diario literario. En el primer caso, como ocurre con el resto de elementos literarios, no se desarrolla un espacio íntimo y el discurso es puramente referencial, mientras que el diario literario desarrolla la figura de un Yo cuya cotidianidad tiende frecuentemente a construir un ámbito privado $\mathrm{y}$, tal vez, íntimo. Lo que lleva a concluir que, efectivamente, el diario que potencia el espacio íntimo requiere para ello de unas estrategias formales, retóricas y, en última instancia, literarias que lo acercan sin lugar a dudas a la perspectiva de la que parte nuestra investigación.

Otro asunto muy distinto, y que aquí no se desarrollará por falta de espacio, es la nueva consideración que en las últimas décadas se le 
ha dado a lo privado. En el nuevo contexto de Internet, como es de sobra sabido, lo privado adquiere una nueva categoría redefinida por el uso de las redes sociales, la aparición de la telerrealidad y, en definitiva, la nueva consideración individual impuesta por las tecnologías informáticas. En un artículo de El País, la joven poeta Luna Miguel (2015) llega a decir en relación al uso de las redes sociales en las nuevas generaciones: "No nos importa que miréis un rato a través de los cristales. Entre todos redefiniremos la intimidad". La construcción de la intimidad en el nuevo texto literario, por tanto, tendrá que llevarse a cabo en relación a un contexto en donde los conceptos de lo público y lo privado están cambiando. Esto no es óbice, sin embargo, para aceptar la imposibilidad de esta construcción, que tendrá una naturaleza literaria tal y como siempre ha tenido desde la aparición de esa forma genérica que aquí hemos denominado diario literario y cuya fecha original puede relacionarse, como se ha dicho, con las publicaciones a lo largo del siglo XIX de los diarios de Samuel Pepys, Benjamin Constant o Henri-Frédéric Amiel.

Lo íntimo del diario literario, en fin, es una construcción textual que se sustenta en elementos autobiográficos y que desarrolla el aspecto privado del Yo diarístico, culminando el proceso de reconstrucción de su identidad. En una definición poco rigurosa pero muy intuitiva, César Aira define la intimidad como "lo que le pasa a uno y le interesa a muchos" (2008: 8). Lo íntimo del diario literario, en este sentido, trasciende la mera subjetividad del autor del texto para convertirse en un elemento universal, y en la medida en que es universal puede interpretarse, recordando aquella distinción aristotélica entre lo histórico y lo poético, como elemento literario. Lo íntimo no es solo lo autobiográfico pasado, sino también, en tanto que parte esencial de la construcción de un personaje modelado a partir de materiales narrativos ${ }^{15}$, lo literario posible; por ello, se puede decir que ejerce como elemento fundamental de la interpretación del diario literario.

15. Resulta de importancia aquí el artículo de Michel Braud (2009), en el que se analizan las posibilidades del diario como relato. 


\section{REFERENCIAS BIBLIOGRÁFICAS}

AIRA, C. (2008). "La intimidad". Boletín del Centro de Estudios de Teoría y Crítica Literaria 13-14, 1-8.

ARANGUREN, J. L. (1989). "El ámbito de la intimidad". En De la intimidad, C. Castilla del Pino (ed.), 17-24. Barcelona: Crítica.

BÉJAR, H. (1989). "La cultura del individualismo". Reis: Revista española de investigaciones sociológicas 46, 51-80.

BORGES, J. L. (2007). Poesía completa. Barcelona: Destino.

BRAUD, M. (2009). "Le journal intime est-il un récit?”, Poetique 160, 387-396.

BRAVO CASTILLO, J. (2003). Grandes hitos de la novela euroamericana, Madrid: Cátedra.

CABALlÉ, A. (2015). Pasé la mañana escribiendo. Poéticas del diarismo español. Sevilla: Fundación José Manuel Lara.

CASTILLA DEL PINO, C. (1989). "Público, privado, íntimo". En De la intimidad, C. Castilla del Pino (ed.), 25-31. Barcelona: Crítica.

(1996). "Teoría de la intimidad". Revista de Occidente 182-183, 1531.

CEDENA GALLARDO, E. (2004). El diario y sus aplicaciones en los escritores del exilio español de posguerra. Madrid: Fundación Universitaria Española.

CORBIN, A. (1991). "El secreto del individuo". En Historia de la vida privada, P. Ariès y G. Duby (eds.), Sociedad burguesa: aspectos concretos de la vida privada 8, 121-203. Madrid: Taurus.

FERNÁNDEZ PRIETO, C. (2015). "Diario e intimidad". Revista de Occidente 406, 49-70.

FOUCAULT, M. (1990). Tecnologías del yo. Barcelona: Paidós. (1999). Estética, ética y hermenéutica. Barcelona: Paidós.

FREIXAS, L. (1995). "La perdida intimidad del diario íntimo". Turia: Revista Cultural 32-33, 34-44.

— (1996). "Amiel o el diario íntimo como género literario". Turia: Revista Cultural 35-36, 46-56.

GIRARD, A. (1996). "El diario como género literario". Revista de Occidente 182-183, 31-38.

GRANELL, M., y DORTA, A. (1962). Antología de diarios íntimos. Barcelona: Labor. 
HIERRO, M. (1999). "La comunicación callada de la literatura: reflexión teórica sobre el diario íntimo", Mediatika 7. 103-127.

KANT, I. (2004). ¿Qué es la ilustración? Madrid: Alianza.

LEJEUNE, P. (1994). El pacto autobiográfico. Madrid: Megazul.

LUCIANI, I. (2013). "Llevar un «libro de cuenta y razón» en la Provenza moderna (siglos XVI-XVIII): escritura doméstica y relato de uno mismo". Manuscrits: Revista d'història moderna 31, 163-203.

LUQUE AMO, Á. (2016). "El diario personal en la literatura: teoría del diario literario". Castilla. Estudios de literatura 7, 273-306.

MIGUEL, L. (2015). "La casa en el árbol”. El País, 12 de junio. Disponible en línea: http://tecnologia.elpais.com/tecnologia/2015/06/12/ actualidad/1434105619_841688.html [18/09/2017].

MONNIER PHILIPPE, M. (1981). "Le dossier Amiel: bilan et perspectives d'un siècle de recherches". Romantisme 32, 91-100.

MORENO, A. (2012). "Las confesiones discretas: el refugio literario de la intimidad”. RILCE: Revista de filología hispánica 28, 74-81.

PARDO, J. L. (1996). La intimidad. Valencia: Pre-Textos.

PERROT, M. (1991). "Formas de habitación". En Historia de la vida y privada, P. Ariès y G. Duby (eds.), Sociedad burguesa: aspectos concretos de la vida privada 8, 7-25. Madrid: Taurus.

PESSOA, F. (2013). El libro del desasosiego. Barcelona: Acantilado.

PICARD, H. R. (1981). "El diario como género entre lo íntimo y lo público". 1616: Anuario de la Sociedad Española de Literatura General y Comparada 4, 115-122.

PINCUS, S. (2013). 1688. La primera revolución moderna. Barcelona: Acantilado.

ROMERA CASTILLO, J. (2000a). "Diarios literarios españoles (19931995)". En Homenaje a José María Martínez Cachero: investigación y crítica, 389-402. Oviedo: Universidad de Oviedo.

(2000b). "Se hace camino al vivir. Diarios de algunos poetas españoles actuales (1975-1993)". En Poesía histórica y autobiográfica (1975-1999): actas del IX seminario internacional del Instituto de Semiótica literaria, teatral y nuevas tecnologías de la UNED, 105118. Madrid: Visor Libros.

(2004). "Algo más sobre la escritura diarística". En Autobiografía en España, un balance, M. Á. Hermosilla Álvarez, y C. Fernández Prieto (eds.), 95-112. Madrid: Visor Libros. 
(2006). De primera mano. Sobre escritura autobiográfica en España (siglo $X X$ ). Madrid: Visor Libros.

SÁNCHEZ TRIGUEROS, A. (2013). El concepto de sujeto literario y otros ensayos críticos. Madrid: Biblioteca Nueva.

SONTAG, S. (2014). Contra la interpretación. Barcelona: Debolsillo.

TORTOSA, V. (2000). "La literatura púdica como una forma de intervención pública: el diario". Signa 9, 581-622.

TRAPIELlO, A. (1990-2015). Salón de pasos perdidos (18 vols.). Valencia: Pre-Textos. (1998). El escritor de diarios. Barcelona: Península.

Recibido el 18 de abril de 2017.

Aceptado el 18 de mayo de 2017. 
